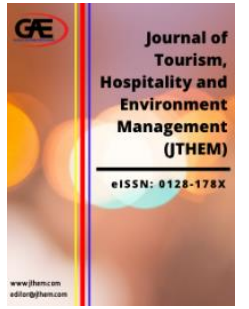

\author{
JOURNAL OF TOURISM, \\ HOSPITALITY AND \\ ENVIRONMENT MANAGEMENT \\ (JTHEM) \\ www.jthem.com
}

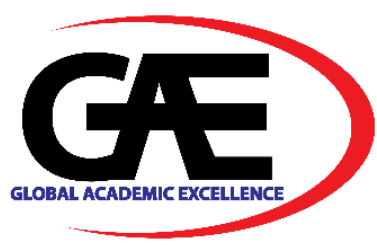

\title{
A FRAMEWORK FOR ENHANCING INTENTION TO RECOVER AND CREDIBILITY OF THE REHABILITATION CENTRE AMONG OLDER ADULTS IN MALAYSIA
} \author{
Lai $^{6 *}$ \\ Faculty of Business, Multimedia University, Melaka, Malaysia \\ Faculty of Business, Multimedia University, Melaka, Malaysia \\ Faculty of Business, Multimedia University, Melaka, Malaysia \\ Faculty of Business, Multimedia University, Melaka, Malaysia \\ Faculty of Business, Multimedia University, Melaka, Malaysia \\ Faculty of Business, Multimedia University, Melaka, Malaysia \\ Email: kplai@mmu.edu.my \\ Corresponding Author
}

Pei Chin Choo ${ }^{1}$, Hishamuddin Ismail ${ }^{2}$, Khong Sin Tan $^{3}$, Chun Teck Lye ${ }^{4}$, Yee Yen Yuen ${ }^{5}$, Kim Piew

\section{Article Info:}

\section{Article history:}

Received date: 13.07 .2020

Revised date: 10.08 .2020

Accepted date: 30.09 .2020

Published date: 01.12.2020

To cite this document:

Choo, P. C., Ismail, H., Tan, K. S., Lye, C. T., Yuen, Y. Y., \& Lai, K. P. (2020). A Framework for Enhancing Intention to Recover and Credibility of The Rehabilitation Centre among Older Adults in Malaysia. Journal of Tourism, Hospitality and Environment Management, 5 (21), 1339.

DOI: 10.35631/JTHEM.521002.

This work is licensed under CC BY 4.0

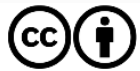

Abstract:

With the growing ageing population in Malaysia and the increasing cost in healthcare, assessing patients' active and healthy states have been recommended by World Health Organization in evaluating the performance of the health recovery system among older adults. However, previous studies on rehabilitation services were 1) mainly conceptual and,2) limited in number as only empirical articles related to hospital management. The purpose of this study is to investigate the antecedents that promote the credibility and the intention to recover among older adults in Malaysia. The study reviews past literature and suggests the antecedents of 1) Health Consciousness, 2) Participation, 3) Financial Security, 4) Physical Environment and 5) Online Learning. The study uses survey research, by adopting previously used questionnaires, to determine the relationships between the stated variables. The data will be collected, analysed, and interpreted via 1) Descriptive analysis, 2) confirmatory factor analysis (CFA), and Structural Equation Modelling (SEM).

Keywords:

Credibility Of The Rehabilitation Centre, Financial Security, Health Consciousness, Intention To Recover, Online Learning, Participation, Physical Environment 


\section{Introduction}

The objective of this study chapter is to illustrate the research background and state the problem of the current study. This section describes the research questions, research objectives and significance of the study. Subsequently, this section concludes with the research scope, definition of the key terms and organisation of the study.

\section{Research Background}

In 2017, 6.2\% of the Malaysian population was 65 years and above and the percentage of older adults in Malaysia is expected to surge to $14.5 \%$ in 2040, in this sense, there will be three older adults for every 20 Malaysians (Department of Statistics Malaysia, 2017). From the above statistics, it showed the composition of population 65 years and above increased from $6.5 \%$ in 2018 to $6.7 \%$ in 2019 . Therefore, the population of older adults will keep increasing by year to year. The growing numbers of older adults have drastically increased the healthcare expenditure of Malaysian government (MIMS, 2017) as the intention to recover is one of the major problems of older adults in Malaysia (The Borneo Post, 2017).

With the growing ageing population in Malaysia and the increasing cost in healthcare, assessing patients' active and healthy states have been recommended by World Health Organization in evaluating the performance of the health recovery system among older adults. In this sense, intention to recover help to return the older adults in the level of the active and healthy, should start off with the promotion of healthy lifestyle among older adults (World Health Organization, 2002). From Malaysia age structure of a community influences a country's prime socioeconomic problem, while nations with older community (more percentage ages 65 and over) need to provide more capital in the health sector.

Although the concept active ageing has been promoted among Malaysian elderly community (Tobi, et. al., 2017), the older adults have been experiencing slow intention to recover from chronic diseases such as diabetes, hypertension and high level of cholesterol (Utusan Online, 2017).

These top 3 mortality cause has been consistently causing two-thirds of the deaths in hospitals (Health Care Asia (2017). All these facts suggested that the current social protection for ageing people in Malaysia is in doubts whether it actually serves the real necessities of older adults (Aziz et al., 2017). Given the fact that RM 1.7 billion has been allocated by Malaysian government in 2017 (The New Straits Times, 2017) to retain and enhance the health recovery to the quality level of the older adults (Warta Daily, 2017), it is vital that this study present the concentration on how credibility of the rehabilitation center could enhance intention to recover among older adults in Malaysia. The older adults require more in terms of healthcare services that have better rehabilitation services to cater for aged care living.

The intention to recover and credibility of the rehabilitation centre among older population refers to the process of optimising opportunities for physical, social and mental self throughout the life course, in order to extend healthy life expectancy, productivity and quality of life among older adults. Although rehabilitation services and intention to recover have been an issue of concern, comparatively few studies have belonged to the aged Malaysia's citizens. Most 


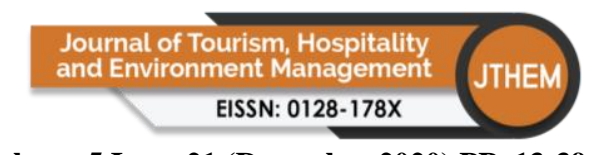

Volume 5 Issue 21 (December 2020) PP. 13-39 DOI 10/35631/JTHEM.521002

studies on older population were focused outside of Malaysia, for instance, the studies of Marquet and Miralles-Guasch (2015), and Fernández-Mayoralas et al. (2015) in Spain and Zaidi et al. (2017) in Europe. Results from the majority of the studies (WHO, 2002; Annear et al., 2014; Fernández-Mayoralas et al., 2015; Marquet and Miralles-Guasch, 2015; Aw et al., 2017; Zaidi et al., 2017) have termed healthy older population to three main pillars, health consciousness, participation and financial security which are the primary antecedents in encouraging people to remain active and independent as they age. Additional two were added later based on their relevancy to the study, i.e. physical environment was suggested by Annear et al. (2014) and online learning by Aw et al. (2017).

\section{Problem Statement}

It is amazing to the correlative vital of research on older adults, given the fact that the older adults have various healthcare demands and depends on inordinate share of health service utilize and disbursement. Thus, it may provide a fundamental issue of 1) whether the existing level of rehabilitation services of government-funded hospitals and clinics that help older adults' intention to recover are sufficient, 2) what are the factors that can be used to improve older adults' intention to recover and to return to the level of active ageing. Prior studies (WHO, 2002; Annear et al., 2014; Fernández-Mayoralas et al., 2015; Marquet and Miralles-Guasch, 2015; Aw et al., 2017; Zaidi et al., 2017) have suggested the 1) Health Consciousness, 2) Participation, 3) Financial Security, 4) Physical Environment and 5) Online Learning. However, there is still lack of comprehensive local studies which link rehabilitation service with patient's intention to recover and active ageing credibility.

Older adults who are health-conscious will aware and take into consideration about their condition of health and are inspired to enhance and/or conserve their standard of life, in addition averting sick health by approaching in healthy performance and existence self-conscious about health (Gould, 1988; Plank and Gould, 1990; Kraft and Goodell, 1993; Newsom et al., 2004). Health consciousness is a strong relationship in main health behaviours would be proposing of a fundamental causal role of intention to avert disease or enhance health, because associations in health performances are indicated by a model positing health consciousness as a general reason (Newsom et al., 2004). Although knowledge, skill, self-efficacy faith, and true or feel obstacle are serious for health behaviour (Newsom et al., 2004), but health concerned incentive is treat a main origin of health behaviour. Therefore, health consciousness plays a vital role in this study.

Participation is the important variable in this study because it helps patient in the way of intention to recover. Patient involvement is postulated as a condition in which the patient applies correspondence to eagerly search detail and take part in common making resolution with health professionals about their medical situation and therapy (Marti \& Renee, 1996). In this collaborative relationship, patient needs cooperation with medical practitioner as a group in order to apply uniform responsibility for health recovery. Patient involvements in life which concern everything happen in their daily are able to help them change their thinking and optimism towards their health issues. This is because they are not self-avoidance to everything happen especially their health problem. Therefore, participant in the social, public and community environment are able to change a person attitude toward particular issues. 


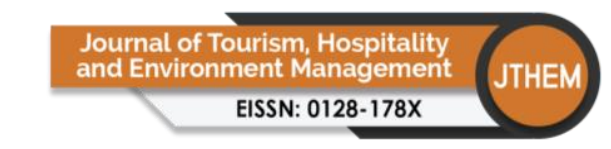

Volume 5 Issue 21 (December 2020) PP. 13-39 DOI 10/35631/JTHEM.521002

Howell et al. (2013) suggest that improve earning and asset can guide to enhance welfare in destitution because money is used to fulfil primary physiological demands. On the basis of Xiao and Noring (1994), financial demand involved to direct expenditure can be considered a lower level need which is physiological demand and financial demand linked to upcoming expenditure can be opinionated as a higher-level need such as security demand. For these causes, the sensation of security generated by an economic permanent such financial safety is a major effect of socio-economic position that influences older adult's intention to recover. Subsequent studies have investigated financial security as a life field contributing to whole health and fulfilment. For instance, Michalos et al. (2005) evaluate determinants of health and life fulfilment and discovery that financial security was a vital guiding principle.

The principle of our health is extremely effected by our physical environment has meet efforts to manage and adjust to the environment become main wisp of public health guidelines from beginning to end of the globe (Morris et al., 2006). This connection between the people health and physical environment have illustrious amongst the cares of worldwide institution containing the World Health Organization (WHO). Therefore, physical environment in health industry has plays an important role. Physical environment in the rehabilitation centre able to influence the patient in term of their intention to recover. Liu et al. (2014) stated the part of physical environments in patient security has obtained evolving professional and public advertency. Baker (2001) has published the quality matter which achievement have been invited to warrantee that quality and secure are merged into health professionals' physical environments (Henriksen et al., 2007).

The implementation of online learning in advance nation has gradually growing in current years with an enhance accessibility of Internet interrelations, local area networks, and Internet Technology support (Tedre et al., 2010; Omidinia et al., 2011; Williams et al., 2011). Since online technology is advance, some of the older adults are starting online learning. With online interactions, older people have the leisure to seek consistent social interactions participated in informal platform (WhatsApp, WeChat and etc) or organised website activities in with familiar or unfamiliar people. While this form of interaction will motivate older people to seek higher levels of social participation, that could gain satisfaction and social integration through online setting. Online learning already becomes a current trend for the society nowadays because people can exchange and seek information through internet.

\section{Research Questions}

1. Does health consciousness affect credibility of the rehabilitation centre and intention to recover?

2. Does participation affect credibility of the rehabilitation centre and intention to recover?

3. Does physical environment affect credibility of the rehabilitation centre and intention to recover?

4. Does financial security affect credibility of the rehabilitation centre and intention to recover?

5. Does online learning affect credibility of the rehabilitation centre and intention to recover?

6. Does credibility of the rehabilitation centre affect intention to recover? 


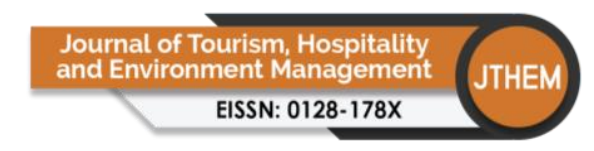

Volume 5 Issue 21 (December 2020) PP. 13-39

DOI 10/35631/JTHEM.521002

\section{Research Objectives}

1. To examine whether health consciousness affect credibility of the rehabilitation centre and Intention to recover.

2. To examine whether participation affect credibility of the rehabilitation centre and Intention to recover.

3. To examine whether physical environment affect credibility of the rehabilitation centre and Intention to recover.

4. To examine whether financial security affect credibility of the rehabilitation centre and Intention to recover.

5. To examine whether online learning affect credibility of the rehabilitation centre and Intention to recover.

6. To examine whether credibility of the rehabilitation centre affect Intention to recover.

\section{Significant of Study}

This research needs to be carried out in this country because this present study will focus more on rehabilitation service. It is a framework that carries five factors to measure the intention to recover in rehabilitation centre. Moreover, this research title is quite vital since most of the older adults are facing the healthcare problem in life when their age is growing. Therefore, the researchers who conduct this research would help to create awareness to the society in our country. Malaysia is a country with different races and cultures, each of the citizens are helping each other. Therefore, the research will contribute to the rehabilitation centre in future.

In addition, researcher and target respondents are able to understand the important of the factors that link together with intention to recover and credibility of the rehabilitation centre. This is because less of the study present together with the marketing field and hospital area. Therefore, through this study area can examine the different result from the previous research. At the same time, this study would help rehabilitation service center, clinic or hospital to understand the perception of the patients and a positive image can be built through the study.

On the other hand, this study will beneficial to the patients and other populations in Malaysia because it also assists the government to enhance the health of citizens in more efficient ways through comprehensive of patient's perceptions, arousal of emotion and behavioural response in a rehabilitation service area. People will more trust and confident in a country when medical system is at a mature stage. Besides that, investors will also have more willingness to invest in Malaysia in order to help more citizens and increase the health level. Future researcher may gain advantage to this study because they can search some information and points that might help them in their research and some of the topic may possible be discussed by this study.

\section{Scope of Study}

The main issue of this study is to enhance of intention to recover and credibility of the rehabilitation Centre among older adults in Malaysia. The older adults (aged 65 years and above) and who are undergoing rehabilitation treatment in the rehab centre and/ or rehab hospitals in Malaysia. Every rehabilitation centre has provided different services such as physiotherapy, otology therapy, occupational therapy, speech and language therapy, cognitive therapy and mental health rehabilitation service. Patient who involve in rehabilitation service will be the target respondent in this research study. There are no specific choose from which disciple. It is following the state and the hospital that the researcher chooses. 


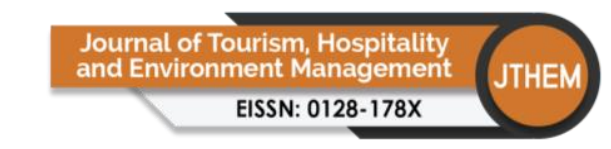

Volume 5 Issue 21 (December 2020) PP. 13-39 DOI 10/35631/JTHEM.521002

Population is defined as the entire group of things, events or people in the interest of the study. According to the demographic world urban areas report, the three most highly concentrated urban areas in Malaysia are Kuala Lumpur, Johor Bahru and Penang (Shivaji, 2015). Therefore, these areas are chosen for target area because it contains high population of the citizen and highly levels of demand on hospital.

Older adults are basically explained corresponding to a range of features i.e. chronological age, change in social role and changes in functional abilities. The study refers older adults as aged 65 years old and above. These groups of target respondent are required to answer the survey questionnaires in order to know their perception in intention to recover. Paper pencil questionnaires are prepared by researcher and require target respondent to answer. Therefore, the survey questionnaires are scope into five variables which stated as health consciousness, participation, financial security, physical environment and online learning. These five variables have relationship with intention to recover and credibility of the rehabilitation centre. Through this survey method, researchers are able to know the perception of patient and it is not an actual measure of intention to recover, i.e. temperature and physical move.

\section{Literature Review}

The study defines the variables related to this research as Health Consciousness, Participation, Financial Security, Physical Environment and Online Learning will be clearly defined in this chapter. Besides that, mediating variable (Credibility of the Rehabilitation Centre) and dependent variable (Intention to Recover) will be described in detail. Moreover, the Relationship Marketing Theory and Stimulus-Organism-Response (SOR) Theory will be explained as well.

\section{Theoretical Background}

\begin{tabular}{|c|c|c|}
\hline \begin{tabular}{l}
\multicolumn{1}{c}{ Stimulus (S) } \\
The Environment Sense, \\
modality variables \\
(eg: colour, temperature)
\end{tabular} & $\begin{array}{l}\text { Organism }(\mathrm{O}) \\
\text { Emotional States } \\
\text { - } \text { Pleasure } \\
\text { - Arousal } \\
\text { - Dominance }\end{array}$ & $\begin{array}{l}\quad \text { Response (R) } \\
\text { Behavioural } \\
\text { Response } \\
\text { - Approach } \\
\text { - Avoidance }\end{array}$ \\
\hline
\end{tabular}

Figure 2.1: Mehrabian And Russell's Approach-Avoidance Model

(Source: Mehrabian and Russell, 1974)

Based on psychology explains, this theory stimulus is the outside elements guiding to the alter of interior conditions of personal (Lim, 2019). Organism is referring to interior cognitive and affective conditions interpose between stimulus and a personal's last react (Wang et al., 2018). Besides that, cognitive condition is the procedure of thought based on data producing (Shaver, 1998), whereas the affective states reflect the emotion or sense (Benlian, 2015). Response means as the effects, answers, reactions and responses. The SOR framework high point the significant part of individual cognitive and affective procedures in reacting to exterior environment change (Wang et al., 2018). That is individual cognitively and affectively evaluate 


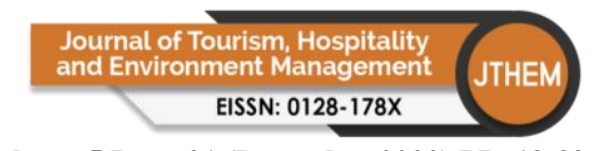

Volume 5 Issue 21 (December 2020) PP. 13-39 DOI 10/35631/JTHEM.521002

stimulus and react to it. Previous studies (Sia et al., 2018; Lai \& Chong, 2020) in health research have drawn on SOR framework to explain how the factors may affect older adults' intention to recover. Mehrabian and Russell's (1974) theory is identify by many researchers as the most advantageous model when describing the effect of surrounding on human behaviour. Feature of the environment like colour, temperature and design will influence individual's emotional state. People will have different cognitive responses to the feature of the service environment (Jang and Namkung, 2009). From this view of perspective, higher temperature will origin a probability of grumpiness, while warm colour and nice design of environment will make people comfortable (Bitner, 1992).

Besides that, the relationship marketing theory exposed to the implementation of the conveying generated by vendors to expand everlasting relationships with clients (Solayappan \& Jayakrishnan, 2010). Communication refer to a major precursor to trust and commitment (Lewin \& Johnston, 1997). In this study, relationship marketing can be treated as an instrument to bring closer and retain older people in a diversification service organisation, thus build up the correlation between the people who provide rehabilitation service and older people (Morgan \& Hunt, 1994). The research establishes based on relationship marketing that involves to the implementation of the conveying allowed between the people who provides rehabilitation service and older people. Relationship Marketing Theory helps this study to a better understanding with the intention to recover and credibility of the rehabilitation centre in term of develop a long-term relationship.

Therefore, we investigate whether health consciousness, participation, financial security, physical environment and online learning affect credibility of the rehabilitation centre and intention to recover in these two theories. Shown that older adults might not able go back to resume therapy when the relationship between factors and the people who provide the rehabilitation service is slackly bound (Godfrey \& Townsend, 2008). It is vitally important to investigate how the roles of believe, service credibility and affective compliance are being effected by rehabilitation centre and how do they assist to the intention to recover.

Figure 2.2 shows the influences of environment stimulus on human behaviour as drawn by Mehrabian and Russell (1974). Moreover, we propound that the surrounding environment in which health consciousness, participation, financial security, physical environment and online learning are developed and the behaviour of older adults in term of credibility of the rehabilitation centre would define the intention to recover. We built this framework to permit us to forecast how older adults understand the diverse effects of factors on characteristics within a given condition. We hypothesise that credibility of the rehabilitation centre able to affect the intention of older adults to resume. Credibility refer to the understand quality of being trusted or conceded as correct, actual or sincere to a certain service (Methaq, 2015). Especially, this study forecasts that credibility will have a mediating influence (as an influence of health consciousness, participation, financial security, physical environment and online learning) on the intention to recover. Among all the health-related services, older adults have comparatively few understandings about their therapy, but with a main central issue on feeling intimation that look like judgement (Sillence and Briggs, 2015) (see Figure 2.2). 


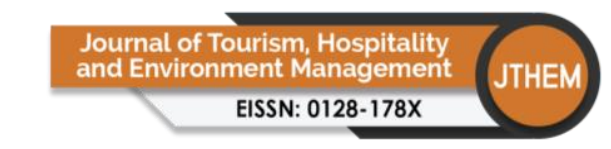

Volume 5 Issue 21 (December 2020) PP. 13-39 DOI 10/35631/JTHEM.521002

\section{Health Consciousness}

Health consciousness refer to an individual's ecological and self-awareness of healthy lifestyles (Karn \& Swain, 2017). Previous studies have suggested that health conscious persons are more responsible for the health (Karn \& Swain, 2017). The World Health Organisation (WHO) defines health as a state of complete physical, mental and social well-being and not merely the absence of disease or infirmity (Khan \& Qureshi, 2018). The individual's daily lifestyle can bring an advantage or disadvantage on health. With a healthy body, humans have the capability to perform daily life activities. This is why a daily health activities is mainly planned and controlled by the individual's choices of lifestyle (Karn \& Swain, 2017). Individuals who are concern health will more engage in searching out preventive, health maintaining attitudes and behaviours in lives in order to feel more responsible in respect to health throughout the lives (Karn \& Swain, 2017).

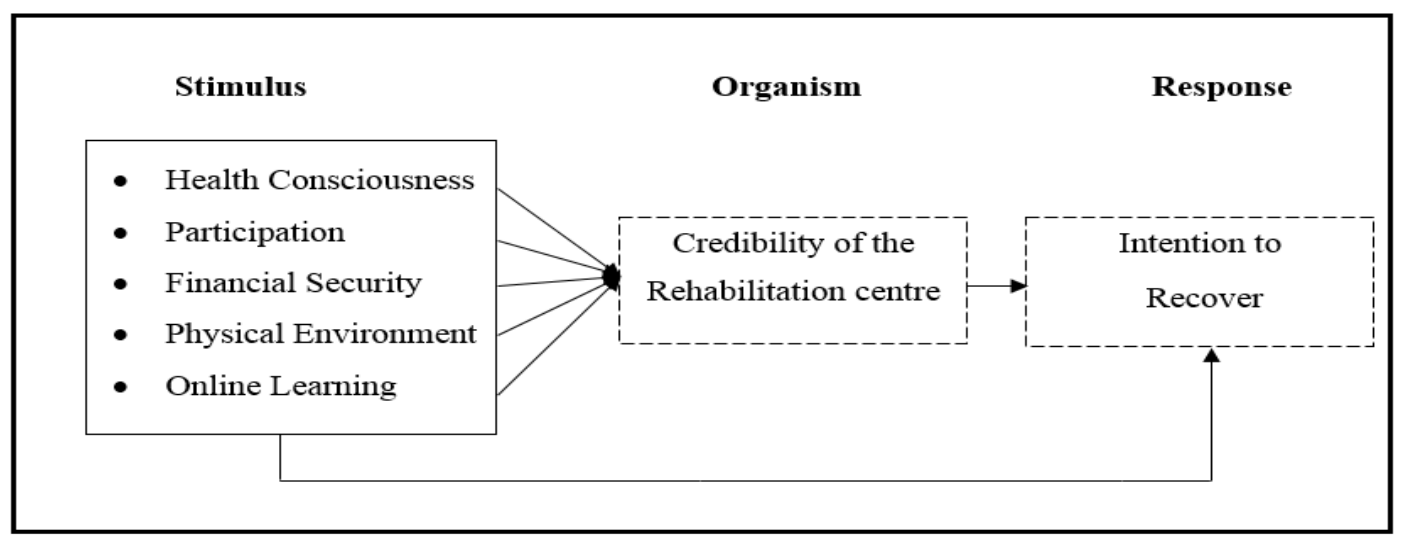

Figure 2.2: Research Framework

Moreover, health consciousness assesses the readiness to undertake health action (Michaelidou $\&$ Hassan, 2008). People who are conscious about health will maintain a good healthy lifestyle such as balanced-diet, exercise regularly and so on. These show that the individual who have health consciousness will concern their health from different aspects and this is an awareness have to build from young. In addition, health consciousness consumers are encouraged to build on health, quality of life and the action of preventing ill health by committing in healthy practices and being self-awareness regarding health (Michaelidou \& Hassan, 2008).

Hong (2011) applies health consciousness as a psychological attribute that is better in capturing individuals' comprehensive orientation towards health (Hong, 2011). Self-awareness is also considered as the first constituent of health consciousness and it gives the tendency of individuals to be attentive on health (Hong, 2011). When people grow older, concern for health and health consciousness are essential in daily lifestyle. Most of the older adults will take seriously on health, because older adults' health recovery requires a longer period than younger people. Past studies have shown that health consciousness is a popular variable for evaluating the result and collecting feedbacks from respondents (Michaelidou \& Hassan, 2008; Hong, 2009; Hong, 2011; Karn \& Swain, 2017).

\section{Participation}

Participation as a person's involvement in a life situation (Coster \& Khetani, 2008). Prior study by Coster and Khetani (2008) demonstrated participation bring the meaning of includes the 


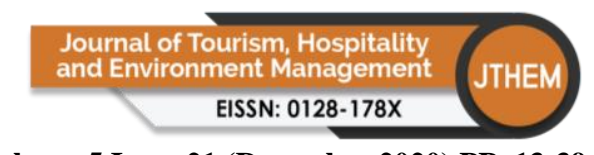

Volume 5 Issue 21 (December 2020) PP. 13-39 DOI 10/35631/JTHEM.521002

thinking of involvement, which may additional be determined as taking part, being incorporate or attracted in an area of life, being received or obtain the needed assets.

In this study, participation includes the older adults' involvement in selecting treatments and conducting medical instructions (Sheldon \& Sherrie, 1984). According to Sheldon \& Sherrie (1984) stated that focused narrowly on the interaction between physician and patients because the patients do not give full consideration towards their care during this interaction. The interaction between the patients and physician would help to improve the participation of patients in receiving rehabilitation service as most of them have a close relationship and better communication with the physician.

Every decision made by patients are important to themselves and physicians, this is because the patients are clearly understanding their own body, and the physicians have a responsibility to understand every patient's condition during the recovery process. Furthermore, given the expected advantages of patient participation, many endeavour have been done to exploit systems or interposition programs devised to bring up more responsibility of patients in the medical experience (Marti \& Renee, 1996). To ensure the achievement of future participation instruments and to enhance present intervention calculates, the action of reject and empirically assess key elements play an importance role in patients' willingness and ability to share accountability with the health care provider (Marti \& Renee, 1996).

Moreover, Alexandris et al. (2018) presented a few types of constraints that might affect motivation, which might also affect participation and subsequent aspects (i.e. from constraints, motivation, participation and subsequent aspects accordingly). Alexandris et al. (2018) mentioned some types of constraint might influence the level of participation indirectly through the positive or negative influence on motivation based on the hierarchical model of leisure constraints proposed by (Crawford et al., 1991). Therefore, it can be concluded that motivation would help to improve patient's willingness and participation in rehabilitation services during the stage of intention to recover.

\section{Financial Security}

Financial security is a significant effect of socio-economic status (e.g., revenue, asset, savings, lack of liability, etc.) that affect subjective welfare particularly among people who have primary needs met (Howell et al., 2013). It very well may be demonstrated by the collection of material possessions or as the capacity to acquire and keep up a specific criterion of living (Howell et al., 2013). The values consist of the traditional structure which has compound honour, family security, and self-discipline, these have all been associated with ethical behaviour (Fritzsche \& Oz, 2007). Financial security reflects the importance of how older adults manage their financial issue and plan their saving in the bank. Likewise, this variable will address the importance of having the sense of independence, as older people may emphasise of being able to make their own choices and fend for themselves. Financial will play as an important antecedent that of concern, will be given priority for active ageing. This variable receives the least attention, as most studies were focused on participation and health consciousness (Haque et al., 2016; Lim \& Thompson, 2016). Thus, investigating this variable will add insights to the development of active ageing in Malaysia. 


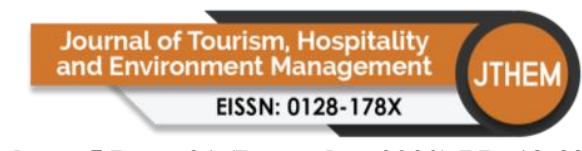

Volume 5 Issue 21 (December 2020) PP. 13-39 DOI 10/35631/JTHEM.521002

Moreover, the patients' sense of security and safety is underline in palliative and treatment care, because this feeling is connection to both physical and mental field of patients (Rostami et al., 2018). The security of patients is within the main liability of healthcare service providers, and offer palliative care by them to enhance patients is very effective in patient's perception of safe and secure (Rostami et al., 2018). The patient who sense safe and secure are more treated, faster discharged, and their therapy costs will be lower. Therefore, financial security is importance in order to build intention to recover. Patients with financial stable are no problem in healthcare service. Therefore, the patient intention to recover will be high compare to those are facing financial problem. Most of the patients are willing to take part in the rehabilitation centre because have high credibility to the services. The patients' sense safe while under healthcare is very vital, hence it is critical to retain and enhance the quality of services provided to them (Rostami et al., 2018).

Furthermore, Songur et al. (2017), mentioned that improve use of evidence-based practices (EBPs) in healthcare services and systems may improve patient situation like ache, lower the expenses of healthcare, and increase patient security in the usefulness of urgency health services. The Institute of Medicine, propose that evidence-based clinical pathways and evidence-based medicine are an effective way of decrease errors in healthcare systems (Son and Özer, 2017). From this view of perspective, the lesser the mistakes made by the service provider would help to improve the security of the patient and increase the credibility of the service at a subsequent time. Patient's financial security is one of the most important factor need to concerned by the healthcare service, and some of the health organisations have frequently been working on progress speculate to train the patient security lifestyle (Son and Özer, 2017).

\section{Physical Environment}

A physical environment can be explained as anything may physically experience through induction such as touch, smell, sight, hearing, and/or taste (Lai \& Chong, 2019). Both natural environment and human-made environment are included in the physical environment. For example, the natural environment, like the air ventilation in the hospital, the water flowing through the pipes, and the trees, flowers, and animals that occur in the yard, as well as the physical environment of a hospital may include the human-made structures for instance the walls, the pipes, and the instrument. One ought to consider the components of the encompassing physical environment when concluding how to associate with that surrounding (Lai \& Chong, 2019)

In addition, it is worthwhile to mention the role of physical environments in developing professionalism and public awareness among patients (Liu et al., 2014). Their studies showed that health care is different from patient-centred, secure, valid, quick, seasonable and fair as it should be (Liu et al., 2014). To issue the quality matter by the Institute of Medicine, attempts have been used to assure that standard and security are merged into health professional's physical environments (Liu et al., 2014). Physical environments reference to the places within which rehabilitation centre projects are take on. The components of physical environment are surrounding environment, living area, accessibility of services and facilities, traffic condition and so on. To find out the implication of places in health care, researcher must investigate the connection between human and the situated environment, and how human utilize the places to equipment movement and convention (Liu et al., 2014). 


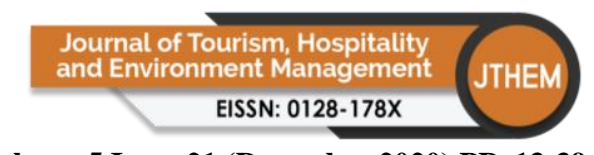

Volume 5 Issue 21 (December 2020) PP. 13-39 DOI 10/35631/JTHEM.521002

Besides that, the factors of discussion rooms and relational places had a main effect on physician and patient interplays. Patients preferred to involve themselves in interacting with physician in a room with larger space but with minimum interpersonal distance (Liu et al., 2014). It showed a better relationship and close between the physicians and patients. Physicians can easily communicate and consult patient when they have a close distance during the discussion and conduct the service. Moreover, physical environment not only related to the surrounding environment of the rehabilitation centre but also linked to acute care facilities, it consider strategies for organizational and employees interventions to decreases medication mistake, it is vital to think over physical environmental factors to have an overall understanding of the issue (Mahmood et al., 2011). Physical environment plays an importance role in easing the process of conducting the rehabilitation service between physicians and patients.

\section{Online Learning}

Online learning is a virtual interaction experience where people who are associated with the peers-to-peers' interactions and are not physically near each other, however can be located at any distance from each other, and interact with learning stages to share information and apply knowledge and abilities for learning evaluation (Whiter, 2020). Online learning is relevant to this study, given that older adults' growing interests of having spent more time in social media interactions and social media sharing activities, that mirrored their social involvement (Levasseur et al., 2010). This is in view that some older people who deal marginalisation and elimination from physical social participation due to their security considerations and being afraid of contacting friends (anti-social). Older people who prefer "comfort-zoning alone" would accustom to the comfort of their inactive routine to manage in social media (Aw et al., 2017). With online interactions, older people have the leisure to seek constant social interplay involvement in unofficial platform (WhatsApp, WeChat and etc) or organised website activities in with familiar or unfamiliar people. While this form of interaction will motivate older people to search higher levels of social participation, that could obtain contentment and social incorporation via online setting.

Besides that, online health communities supply access to information and coordinate social interplay; they build up a different solution for patients' needs, for example that they likely enhance the welfare of people and community as a whole (Van Oerle et al., 2016). Patient who involve in the online interaction, will gain more knowledge and information through social media. This is because patients can through different way of social media to obtain the information. For example, patients who have social media interaction with their friends or specialist, they can easily communicate and exchange information with each other.

Notwithstanding questions over the credibility online commentary of physicians continue to increase in popularity (Saifee et al., 2019). From this view of perspective, many people face difficulty to justify the validity and reliability of the physician's credential via the internet. In a recent survey, the report showed that $28 \%$ strongly agreed that a positive online commentary of a physician would cause them to search care from that physician, while another $27 \%$ showed that a negative review would cause them to prevent that physician altogether (Saifee et al., 2019). This premise is relevant, yet it requires further examination to clarify the role of online participation, in the condition of rehabilitation services, and whether online participation helps older adults acquire healthcare related information. 


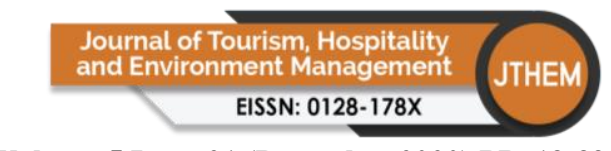

Volume 5 Issue 21 (December 2020) PP. 13-39 DOI 10/35631/JTHEM.521002

\section{Credibility of the Rehabilitation Centre}

Credibility is the perceived quality of being trusted or conceded as true, genuine or sincere to a given service (Methaq, 2015). In this study, the applicability of rehabilitation services within the concept of credibility (Methaq, 2015). There are two major elements of the credibility to investigate, which are trustworthiness and expertise. Trustworthiness is the older adults' credibility on a given rehabilitation activity which will satisfy its commit and the mastery ability that helps older adults facing ageing situation (Sia et al., 2018). From previous research, expertise identifies as a cycle of determine challenging tasks, engaging in intensive practice, receiving feedback, and having the chance for correction and iterance (Goldman, 2008).

The confidence of the older adults will be reflected by the trustworthiness and expertise. Based on the credibility of the rehabilitation centre, it can be evaluated as the most vital driver for performing an substitute or be a semaphore to influence the older adults' decision (Seyed \& Tahernejad, 2012). Older adults, who have strong trustworthiness in the healthy ageing mind set, will trust the service rendered by the government and evolve a positive attention toward the government and other health service routes. Credibility of the rehabilitation centre might be considered as an advantageous characteristic and referred that the older adults will have a better chance to engage with the same activities for improving their healthy lifestyle in future.

\section{Intention to Recover}

Intention to recover refer to a person's goal or plan to go back to the beginning (Lai \& Chong, 2020). Therefore, people have opinion to recover after injury. In 2007, both the Betty Ford Institute and the centre for Substance Abuse Treatment presented comprehensive explanation on recovery based on panels gathered by these organizations; these separately explained recovery as a willingly retained lifestyle identify by sobriety, people health, and community (Betty and Panel, 2007), or as a process of change through which a people implements temperance and enhanced health, wellness and standard of life (Young et al., 2007).

There is the existence of relationship between these five variables (Health Consciousness, Participation, Financial Security, Physical Environment and Online Learning) and older people's intention to recover. Although there is limited evidence to demonstrate the link between all the five variables on intention to recover, a strong evidence is available for a positive association with persons in having better perception of health concern, active participation, financial security and environment reporting higher levels of satisfaction (Lee \& Kasper, 1998), cognitive impairment (Wu et al., 2015), improving physical activity (Cabrita et al., 2016), that addresses a positive impact on their recovery.

In addition, recovery is required for a healthy and balanced life besides for the capability to stay engaged and recharge individual energy resources (Ejlertsson et al., 2018). Recovery, considered as an association of recovery during working hours and outside work, had the highest connection to respondent's perceived health status (Ejlertsson et al., 2018). Even though previous studies have reported that there is a connection between recovery, physical and mental conditions, but most of the research works only accentuate on recovery outside work, and one recent study has explained on how the physical and psychological distance from work and work-related feelings or thoughts is crucial to the recovery experience (Ejlertsson et al., 2018). 


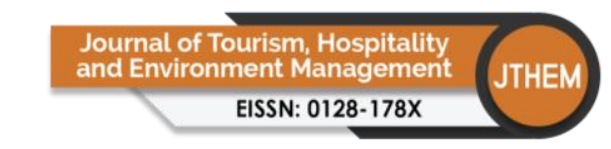

Volume 5 Issue 21 (December 2020) PP. 13-39 DOI 10/35631/JTHEM.521002

\section{Research Framework}

Intention to recover and credibility of the rehabilitation services among older population refers to the process of optimising opportunities for physical, social and mental self throughout the life course, in order to develop healthy life expectancy, productivity and quality of life among older people. Although rehabilitation services and intention to recover have been an issue of concern, relatively few studies have pertained to the older Malaysia's population. Most studies on older population were focused outside of Malaysia, for instance, the studies of FernándezMayoralas et al. (2015) and Marquet and Miralles-Guasch (2015) in Spain and Zaidi et al. (2017) in Europe. Results from the majority of the studies (WHO, 2002; Annear et al., 2014; Fernández-Mayoralas et al.,2015; Marquet and Miralles-Guasch, 2015; Aw et al., 2017; Zaidi et al., 2017) have termed healthy older population to three main pillars, health, participation and security which are the primary antecedents in motivating people to maintain active and independent as their age. Additional two were added later based on their relevancy to the study, i.e. Physical Environment was suggested by Annear et al. (2014) and Online Learning by Aw et al. (2017).

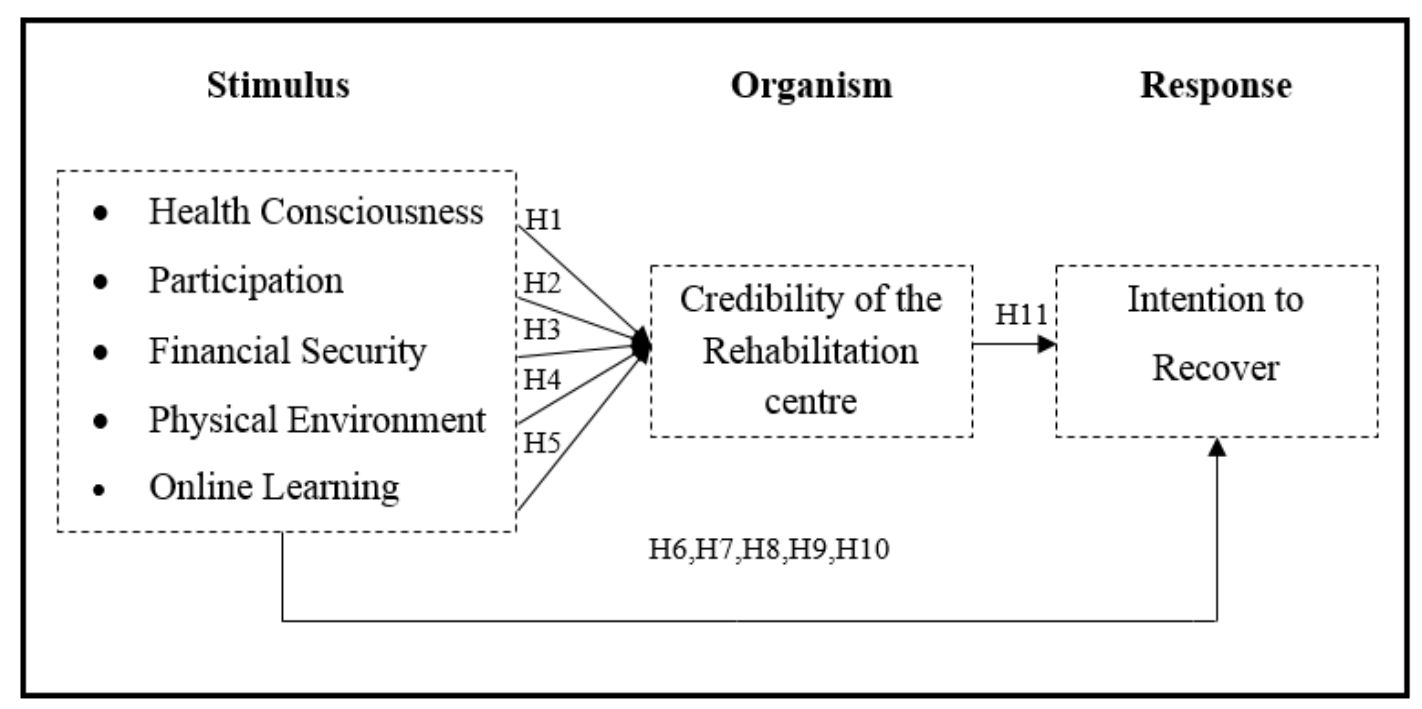

Figure 3.1: Research Framework

\section{Hypothesis Development}

This study has six research questions that will be examined in Chapter 4's data analysis. There are total eleven hypotheses that have been derived and are stated below.

\section{Relationship between Health Consciousness and Credibility of the Rehabilitation Centre}

Nowadays, many people concern about health. There are diverse elements which interaction with, and which influence health at unsimilar levels, be it on the people body and spirit, be it in germs on the miniaturized scale level, or financial status at the full-scale level (Karn \& Swain, 2017). Therefore, patient who concern health-conscious will involve more in searching healthier behavioural in sequences enhance their overall health.

Despite the significant influence of medicine in present health's culture, clinical practice has always unable to contain the uncontrollable growth of implication pertaining to health (Crawford, 2006). All patients believe and energetic patients participant are appropriate in their 


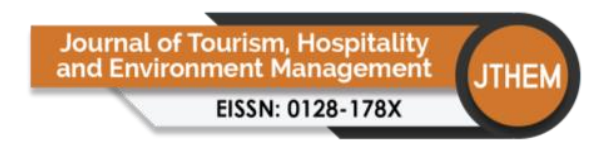

Volume 5 Issue 21 (December 2020) PP. 13-39 DOI 10/35631/JTHEM.521002

own authority and because they are correlated with enhanced health results (Trachtenberg et al., 2005). Thus, hypothesis is developed:

H1: The element of health consciousness positively affects the credibility of the rehabilitation centre.

\section{Relationship between Participation and Credibility of the Rehabilitation Centre}

In an epoch of same chance and higher education, patients began to request more manipulate over their medical care (Marti \& Renee, 1996). From this view of perspective, patient participation is still high in their medical care. Patients' trust in physicians may mediate the relationship between patient characteristics and participation preferences (Arora \& McHorney, 2000). From the above statement, we know that patient come with greater trust will desire less control during visit. On the other hand, older patient and less well-educated patient will have more believe in physicians this is because patients' confidence in their physicians' knowledge and technique is an assembly of trust. We assume that an intervention enhancing patient participation in medical care decisions could improve clinical surveys of disease activity and health-related quality of life (Greenfield et al., 1986). Thus, hypothesis is developed:

$\mathrm{H} 2$ : The element of participation positively affects the credibility of the rehabilitation centre.

\section{Relationship of Financial Security and Credibility of the Rehabilitation Centre}

Consecutive studies have investigated financial security as a life area devoting to general health and fulfilment (Howell et al., 2013). Therefore, financial security and life satisfaction have a huge relationship in our life. In a family, the person who control the financial will have more responsibility to make sure the family members are in the satisfaction condition. Nowadays, financial security already become an important issue in our daily life activity. The previous study has suggested that health, life fulfilment and financial security are vital reference (Howell et al., 2013). From this view of perspective, health will be better and better when people are allowed financial support. For example, a patient who are in illness condition and enough financial support will willing to accept and believe in hospital treatment to control their condition otherwise they are not to accept any treatment. Thus, hypothesis is developed:

H3: The element of financial security positively affects the credibility of the rehabilitation centre.

\section{Relationship of Physical Environment and Credibility of the Rehabilitation Centre}

To discuss the quality matters announced by the Institute of Medicine, influences have been made to assure that quality and security are merged into health professionals' physical environments (Liu et al., 2014). Therefore, the surrounding physical environment of the hospital have made greater confident to the patient. Patient's credibility can build up from the physical environment of the hospital. The physical environment provides cues and opportunities for physical activity (Giles-Corti \& Donovan, 2002). Besides that, patients can enjoy their treatment and physical activity in the comfortable environment at the same time they can relax their body and mind. Thus, hypothesis is developed: 


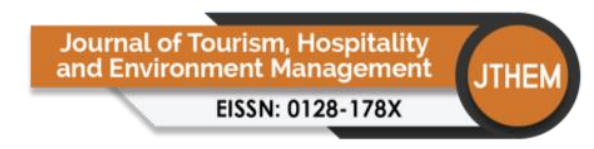

Volume 5 Issue 21 (December 2020) PP. 13-39 DOI 10/35631/JTHEM.521002

H4: The element of physical environment positively affects the credibility of the rehabilitation centre.

\section{Relationship of Online Learning and Credibility of the Rehabilitation Centre}

The internet is a uniquely accessible, time unconstrained, easy to use and economical portal for health detail (Leitan et al., 2015). Therefore, this is the efficiency method that the patient can get the latest information from online searching. There is also prove that human are more willing to self-exposure online and internet is a desirable and productive way to transfer treatment (Leitan et al., 2015). Thus, online learning is the current trend to add in this research framework. As compared to face-to-face interaction, people with mental-illness prefers to access health-related information via internet. (Leitan et al., 2015). As such, most of the patients will search online when they get to know they have health problem rather than visit to doctor immediately. Patient's credibility towards hospital's service would increase when the online information is coincided with the advices from doctor. Hence, hypothesis is developed:

H5: The element of online learning positively affects the credibility of the rehabilitation centre.

\section{Relationship of Health Consciousness and Intention to Recover}

Health is envisaged as the situation of probability for the better life or even the better life itself, it make health conscious people concern about healthcare understanding for the undercover to postpone the last terminal point; yet in addition for something else: the scheme to a living free of disease, ache or affliction (Crawford, 2006). Sharing experiences through stories has become a central practice within recovery-based healthcare and story sharing has been used to enhance the empathy and understanding of healthcare staff and as a mechanism of peer support (Llewellyn et al., 2019). Therefore, patients who received recovery process can share their own stories and experience to physician. By this, healthcare staff will clearer and easier to help patient in the recovery journey. In addition, patients who are concern to their health will easy to follow the instruction from the physician. Thus, hypothesis is developed:

H6: The element of health consciousness positively affects the older adults' intention to recover.

\section{Relationship of Participation and Intention to Recover}

Participation is an vital long-term output from medical, rehabilitation, and social service programs that provide necessary supports to those individuals who undergoes impairment caused by injury, birth defect, physical or mentally disorder, or aging in a environment with lower quality as compared to their or society's expectation (Heinemann, 2010). Therefore, patients must accept and willing to involve themselves in recovery stage. This is the special service that the rehabilitation centre provides to those particular patients. Patients who are not willing to consult the professional physician, they are lose the opportunity to know their current condition and the right treatment to the disease. Also, older and less well-educated patients have greater trust in physicians (Arora \& McHorney, 2000). Patient's confidence in their physician's knowledge and skills is an element of credibility. Thus, hypothesis is developed:

H7: The element of participation positively affects the older adults' intention to recover. 


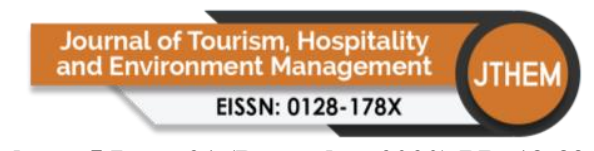

Volume 5 Issue 21 (December 2020) PP. 13-39 DOI 10/35631/JTHEM.521002

\section{Relationship of Financial Security and Intention to Recover}

A person's real changes in reserve fund may dissimilar from arranged changes because of unpredicted incidents that decidedly or contrarily influences whole reserve fund (Kim \& Lyons, 2008). Financial security is very important, and it reflects the overall factors in our life such as support family members, daily expenses, life satisfaction and so on. Therefore, this study is variorum on the effect that health issues have on financial stress (Kim \& Lyons, 2008). From this statement, we know that many patients are chosen to escape from their health problem. The mainly reason is because of their financial security not support to the current condition. Yet, improving economic level may also support humans fulfil their advanced order needs and it may be positively pertaining with social support, allowing peoples to satisfy their need for belongingness (Howell et al., 2013). Thus, hypothesis is developed:

H8: The element of financial security positively affects the older adults' intention to recover.

\section{Relationship of Physical Environment and Intention to Recover}

Promoting physical activity is a public health preference, and changes in the environmental contexts of adults' activity options are trusted to be critical (Humpel et al., 2002). Physical environments indicate the occupied space where clinical services or activities are conducted. Other than understand how people utilize the places to facilitate activities and practice, we have to find out the connections between individual and their situated environments in order to improve the understanding on important of spaces in healthcare. (Liu et al., 2014). The physical environment of the hospital is design based on the patient's perspective such as toilet, aisle, equipment for rehab and so on. This bring convenience to the patients who came for rehabilitation service. Physical environment elements have direct relationship with physical activity behaviour (Humpel et al., 2002). In addition, good environment and service that provide to patient will add on many advantages to their recovery journey. Hence, hypothesis is developed:

H9: The element of physical environment positively affects the older adults' intention to recover.

\section{Relationship of Online Learning and Intention to Recover}

The increment of social media detail created by Internet users and hosted by popular sites such as Facebook, Twitter, YouTube, Wikipedia, and blogs has brought some new hazards for medical professionalism (Greysen et al., 2010). Nowadays, these all social media application is spread rapidly. People can simply search any relevant information from the network. It is no true or false in term of these information. But, patients need professional information in the area of medical especially on their health condition. In some special cases, online searching really help a lot to public in term of spread the news. Social media as a technology which can public the news or information in wide and it has capability to change method in interconnection with the physicians and single patient, physicians must think over the significance of their professional compliance (Greysen et al., 2010). From this view of perspective, intention to recover is related to patient's life so it must consult to professional physician. Thus, hypothesis is developed:

H10: The element of online learning negatively affects the older adults' intention to recover. 


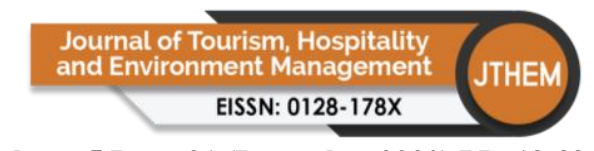

Volume 5 Issue 21 (December 2020) PP. 13-39 DOI 10/35631/JTHEM.521002

\section{Relationship of Intention to Recover and Credibility of the Rehabilitation Centre}

All patients believe and energetic patients participant are appropriate in their own authority and because they are correlated with enhanced health results (Trachtenberg et al., 2005). This is true while patient's credibility high toward rehabilitation centre and their involvement in intention to recover will increase. There are a lot of studies investigate either patient believe or patients' roles in searching care, level of participation in medical decisions, and adherence to therapy (Trachtenberg et al., 2005). From this view of perspective, patients willing to seek a good rehabilitation centre or physician in order to help them in medical treatment. The professional level of the physician and the service provided to the patient will affect their selection. Both level of confidence in the medical profession and fulfilment with care are important for patient to involve in medical care. Hence, hypotheses is developed:

H11: Perceived intention to recover positively affects the credibility of the rehabilitation centre among older adults.

\section{Sampling Design}

Three target areas will be chosen in this research. According to the demographic world urban areas report, the three most highly concentrated urban areas in Malaysia are Kuala Lumpur, Johor Bahru and Penang (Shivaji, 2015). These three areas constitute the three highly levels of demand on hospital. Research has target each of the area with 150 target respondents. This study is using a survey approach, and the data were collected by using a questionnaire that was designed. This is because a survey approach can help to understand the general picture from the point of view of a large number of respondents. With the statistical results, it can evoke discussion that corresponds to the research objectives. This section will help the reader to understand the target population, the sampling methods and finally the sample size.

\section{Target Population}

Population is defined as the entire group of things, events or people in the interest of the study. This research studies the rehabilitation service in the rehabilitation centre or hospital. According to the demographic world urban areas report, the three most highly concentrated urban areas in Malaysia are Kuala Lumpur, Johor Bahru and Penang (Shivaji, 2015). These three areas constitute the three highly levels of demand on hospital.

In addition, patients who had visited rehabilitation service in the states of Kuala Lumpur, Johor Bahru, Penang and other states were selected as the target respondents. The older adults (aged older than 65 years) and who are undergoing rehabilitation treatment in the rehab centre and/or rehab hospitals in Malaysia are the target respondent for this study. The respondents in all disciple of the rehabilitation centre will target as a respondent, no specific from which disciple of rehabilitation and follow by the hospital that the researcher choose.

\section{Sampling Design Method}

The study aims to examine the antecedents that promote intention to recover and service credibility among older adults in the rehabilitation centres/ hospitals in Malaysia. The study defines the design of the study as a descriptive study, i.e. a study that examines the perceptions of older adults toward the potential antecedents that may promote faster intention to recover and service credibility. 


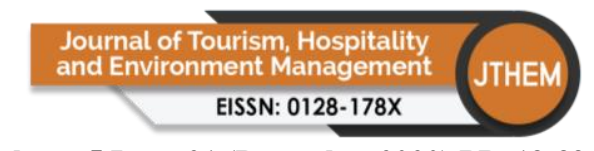

Volume 5 Issue 21 (December 2020) PP. 13-39 DOI 10/35631/JTHEM.521002

Besides that, purposive sampling which under non-probability sampling is used in this study this is because researcher is more likely to get the opinion from target population. Researcher comes with purpose in mind and get to know which group of the peoples are their target respondent. The study employs survey method, as the means to elicit the perception of older adults in the rehab centres/ hospitals. The study applies a cross sectional survey, given that this survey method allows the study to draw relevant characteristics of a population at one time. Inclusion criteria in this study are as follow:

- $\quad$ All older adults (aged 65 and above).

- Older adults are undergoing rehabilitation treatment in the rehabilitation centre and/or rehab hospitals in Malaysia at least 3 times.

- $\quad$ The older adults who are willing to participate in this study.

- Those target respondents who have intention to recover are also including as a respondent for this research. This is because researcher can easily communicate and receive their opinion and feedback based on their observation in the survey questionnaires.

- Older adults who are no mental health problem and able communicate with the researcher.

\section{Sample Size}

Sample size is a major factor for determining the statistical significance (Hair et al., 2010). First, 200 target respondents will prepare for the pilot test. Pilot test is a form of the primary examination in a smaller sample population and to validate the measurement scales of the survey (Mubashir et. al., 2010). Second, researcher will target 400 respondents for confirming and hypotheses testing. The sample size calculation for final study is $72 \times 5=360$ sample size. The calculation is based on minimum 5 cases to each study item and suggested by (Pallant $\&$ Bailey, 2005; Tabachnick et. al., 2007). So that, the researcher targets 200 sample size for pilot test and 400 sample size for the final study to the other considerations discussed next suggested by Hair et al 2010.

\section{Operational Definition of Constructs}

Variables that were included in the research framework will be given their meanings so that they may be manipulated and measured. Table 3.1 shows the operation definitions of each variable along with its related references.

\begin{tabular}{|c|c|c|}
\hline Construct & Definition & $\begin{array}{c}\text { Related } \\
\text { References }\end{array}$ \\
\hline $\begin{array}{l}\text { Health } \\
\text { Consciousness }\end{array}$ & $\begin{array}{l}\text { Health consciousness refers to an individual's concern, } \\
\text { and interest in information about physical, emotional, } \\
\text { and social health and self- realization of their true } \\
\text { potential. }\end{array}$ & $\begin{array}{l}\text { (World Health } \\
\text { Organization, } \\
\text { 2002; Karn \& } \\
\text { Swain, 2017; } \\
\text { Khan \& Qureshi, } \\
\text { 2018) }\end{array}$ \\
\hline Participation & $\begin{array}{l}\text { Participation is defined in the International } \\
\text { Classification of Functioning, Health, and Disability } \\
\text { (ICF) as "involvement in a life situation," while its } \\
\text { converse, participation restrictions, are defined as }\end{array}$ & $\begin{array}{l}\text { (Heinemann, } \\
\text { 2010) }\end{array}$ \\
\hline
\end{tabular}




\begin{tabular}{|c|c|c|}
\hline & $\begin{array}{l}\text { "problems an individual may experience in } \\
\text { involvement in life situations." }\end{array}$ & \\
\hline $\begin{array}{l}\text { Financial } \\
\text { Security }\end{array}$ & $\begin{array}{l}\text { Financial security is an important outcome of socio- } \\
\text { economic status (e.g., income, wealth, savings, lack of } \\
\text { debt, etc.) that influences subjective well-being } \\
\text { particularly among people who have basic needs met. }\end{array}$ & $\begin{array}{l}\text { (Howell et al., } \\
2013 \text { ) }\end{array}$ \\
\hline $\begin{array}{l}\text { Physical } \\
\text { Environment }\end{array}$ & $\begin{array}{l}\text { Physical environment is a space in which clinical } \\
\text { activities are undertaken. }\end{array}$ & (Liu et al., 2014) \\
\hline $\begin{array}{l}\text { Online } \\
\text { Learning }\end{array}$ & $\begin{array}{l}\text { A virtual learning experience where individuals who } \\
\text { are involved in the learning are not located physically } \\
\text { close to one another, but can be located at any distance } \\
\text { from one another, and interact with learning platforms } \\
\text { to share information and apply knowledge and skills for } \\
\text { learning assessment. }\end{array}$ & (Whiter, 2020) \\
\hline $\begin{array}{l}\text { Credibility of } \\
\text { the } \\
\text { Rehabilitation } \\
\text { Centre }\end{array}$ & $\begin{array}{l}\text { Credibility is the perceived quality of being believed or } \\
\text { accepted as true, real or honest to a certain service. }\end{array}$ & aq, 2015) \\
\hline $\begin{array}{l}\text { Intention to } \\
\text { Recover }\end{array}$ & $\begin{array}{l}\text { The intention of older adults to possess a good health } \\
\text { behavioural response after receiving the health-related } \\
\text { service and consider engaging the same service } \\
\text { provider in future. }\end{array}$ & $\begin{array}{l}\text { (Staats et al., } \\
\text { 2003) }\end{array}$ \\
\hline
\end{tabular}

\section{Measurement Items}

The study applied five Likert scale items (from $1=$ strongly disagree to $5=$ strongly agree) to evaluate each respondent's perception (Leung, 2011). Measurement items are adapted from the past studies which are related to rehabilitation service and filtered through the face validity from three experts. This research had conducted face validity to ensure that the measurement items would be valid and reliable for patient's perception. Face validity is a measurement method by experts to determine how representative the questions designed for a study are. To have accurate items to measure the variable in the patient perception, this research adapted the questions from the literature about rehabilitation service in related field. For this dissertation, a face validity test was conducted by one professor and two doctoral lecturers in the related field. After the discussion, several questions were deleted for being duplicative or irrelevant. The outcomes are presented in the appendix.

\section{Pilot Study}

According to Babbie (2013), a pilot test is to check he relevance of variables and to develop the questionnaires. It can assist in identifying the weaknesses of the instruments for a study before a larger-scale study is undertaken. A reliability test is a measurement method that involves using analysis software to examine the consistency of responses to the questions. The study used Statistical Package for the Social Science (SPSS) analysis software to measure the reliability of each variable.

\section{Data Analysis Method}

A two-level study is employed for this study i.e. Pilot Test, for exploring the antecedents and Final Study, for confirming the model via Confirmatory Factor Analysis and Structural 


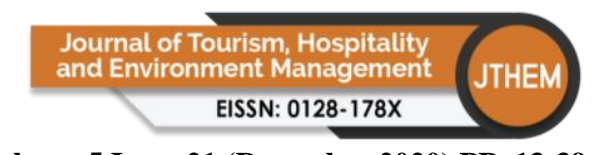

Volume 5 Issue 21 (December 2020) PP. 13-39 DOI 10/35631/JTHEM.521002

Equation Modelling. The measurement scales of the five variables will be adapted from the studies of Roslan et al. (2016). Subsequently, the study will employ SPSS (Statistical Package for the Social Sciences) and AMOS (Analysis of Moment Structures) for model confirmatory, structural equation modelling and hypotheses testing.

AMOS statistic solution is another statistical analysis plan that researcher will use to analysis the data in this research. AMOS is statistical software and it stands for analysis of a moment structures. AMOS is an added SPSS module, and is specially used for Structural Equation Modelling (SEM), path analysis, and confirmatory factor analysis (CFA). Confirmatory Factor Analysis has contained Validity Test, Reliability Test and Fitness of Measurement Model Test. It is also known as analysis of covariance or causal modelling software. AMOS is a visual program for structural equation modelling (SEM). In AMOS, we can draw models graphically using simple drawing tools. AMOS quickly performs the computations for SEM and displays the results.

\section{Descriptive Analysis}

Descriptive analysis was calculating using the SPSS to organize the general properties of the data. Inferential statistics were also involved in the analysis to assist the researcher to identify the dispersion as well as central tendency (Karlsson, 2016). During the analysation, the demographic data and characteristics of respondents have been summarized.

\section{Confirmatory Factor Analysis (CFA)}

Hair et al. (2014) explained that CFA is a statistical technique that examines the proposed theory or model and identifies the best model fit. CFA confirms the unidimensional of scales and also prescribes the relationship among constructs (Gefen and Straub, 2005).

\section{Validity}

Validity refers to the ability of the instruments to examine a structure (Hair et al., 2014). The following methods are applied in this research to evaluate the validity of the constructs. Convergent validity is a validity instrument that works only when the factors of measurement model are statistically significant and correlated. Convergent validity could be verified with Average Variance Extracted (AVE). It is a measurement to examine the coefficient of two factors. Hair et al. (2014) stated that the value of AVE should be greater than 0.50, to assume convergent validity. Discriminant validity is an intra-relationship evaluation. It examines the extent to which the constructs could discriminant from other constructs. It could be identified by using the square correlation of each pair compared with the AVE of the respective constructs. AVE should exceed the square correlation coefficient of the relevant constructs to assume discriminant validity (Hair et al., 2014).

\section{Reliability}

Reliability is the ability of the instruments to conclude that the respondents are giving consistent results or perceptions in response to the questions. High reliability means greater accuracy of the items. Construct reliability refers to the elimination of the internal consistency of the measurement items that represent the construct. When it is greater than 0.70 , construct reliability is achieved (Hair et al., 2014). 


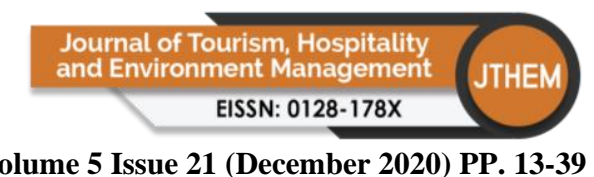

Volume 5 Issue 21 (December 2020) PP. 13-39

DOI 10/35631/JTHEM.521002

\section{Fitness of Measurement Model}

In structural equation modelling (SEM), a series of goodness-of-fit indexes is used to measure the model fitness to the construct of the data at hand (Hair et al., 2014). This is an important part of the analysis since it helps to determine whether the model being tasted is acceptable. Hair et al, (2014) recommended that at least three indexes from all the indexes constitute the requirement to say that the model is representative.

\section{Summary}

This chapter explained how the research framework and hypotheses were developed. The relationship between independent variables and dependent variable were expected to be mediated by credibility of the rehabilitation. This chapter also described in detail the development of the questionnaire for this study. In this study, descriptive analysis, factor analysis, confirmatory factor analysis (CFA), reliability test and Structural Equation Modelling (SEM) were used to analyse and interpret data. The next chapter presents the results of the mai3n study.

\section{Acknowledgements}

The authors would like to thank the Ministry of Education, Malaysia for funding this research (Fundamental Research Grant Scheme-FRGS/1/2018/SS03/MMU/03/4).

\section{References}

Alexandris, K., Tsorbatzoudis, C., \& Grouios, G. (2002). Perceived constraints on recreational sport participation: Investigating their relationship with intrinsic motivation, extrinsic motivation and amotivation. Journal of Leisure Research, 34(3), 233-252

Annear, M., Keeling, S., Wilkinson, T., Cushman, G., Gidlow, B., \& Hopkins, H. (2014). Environmental influences on healthy and active ageing: A systematic review. Ageing \& Society, 34(4), 590-622.

Arora, N. K., \& McHorney, C. A. (2000). Patient preferences for medical decision making: who really wants to participate?. Medical care, 38(3), 335-341.

Aw, S., Koh, G., Oh, Y. J., Wong, M. L., Vrijhoef, H. J., Harding, S. C., \& Hildon, Z. J. (2017). Explaining the continuum of social participation among older adults in Singapore: from closed doors to active ageing in multi-ethnic community settings. Journal of aging studies, 42(2017), 46-55.

Aziz, N. A. B., Ahmad, Y., \& Zainuddin, A. (2017). The Evolution of Government Attention Towards Older Person in Malaysia: A Critical Review of Malaysia 5 Years Plan. Journal of Administrative Science, 14(2), 1-12.

Babbie, E. (2013). The basics of social research. Boston: Cengage Learning.

Baker, A. (2001). Crossing the quality chasm: a new health system for the 21 st century. British Medical Journal Publishing Group, 323(7322), 1192.

Benlian, A. (2015). Web personalization cues and their differential effects on user assessments of website value. Journal of Management Information Systems, 32(1), 225-260.

Betty, T., \& Panel, C. (2007). What is recovery? A working definition from the Betty Ford Institute. Journal of Substance Abuse Treatment, 33(3), 221-228.

Bitner, M. J. (1992). Servicescape: The Impact of Physical Surroundings on Customers and Employees. Journal of Marketing, 56 (2), 57-71.

Cabrita, M., Tabak, M., and Vollenbroek-Hutten, M. M. R. (2016). Technology based interventions to promote Healthy and Active Ageing: the role of positive emotions and 


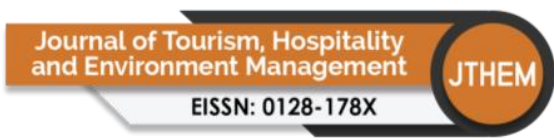

Volume 5 Issue 21 (December 2020) PP. 13-39 DOI 10/35631/JTHEM.521002

physical activity. In Doctoral Consortium on Information and Communication Technologies for Ageing Well and e-Health (DCICT4AWE 2016), SCITEPRESSScience and Technology Publications, Lda. 3-9

Crawford, D. W., Jackson, E. L., \& Godbey, G. (1991). A hierarchical model of leisure constraints. Leisure Sciences, 13(4), 309-320.

Crawford, R. (2006). Health as a meaningful social practice. An Interdisciplinary Journal for the Social Study of Health, Illness and Medicine, 10(4), 401-420.

Coster, W., \& Khetani, M. A. (2008). Measuring participation of children with disabilities: Issues and challenges. Disability and Rehabilitation, 30(8), 639-648.

Department of Statistics Malaysia (2017). Population and Demographics: Ageing. Retrieved February 16, 2018, from https://www.dosm.gov.my/v1/uploads/files/6_Newsletter/Ageing. pdf.

Ejlertsson, L., Heijbel, B., Ejlertsson, G., \& Andersson, I. (2018). Recovery, work-life balance and work experiences important to self-rated health: A questionnaire study on salutogenic work factors among Swedish primary health care employees. Work, 59, $155-163$.

Fernández-Mayoralas, G., Rojo-Pérez, F., Martínez-Martín, P., Prieto-Flores, M. E., Rodríguez-Blázquez, C., Martín-García, S., \& Forjaz, M. J. (2015). Active ageing and quality of life: factors associated with participation in leisure activities among institutionalized older adults, with and without dementia. Aging \& mental health, 19(11), 1031-1041.

Fritzsche, D. J., \& Oz, E. (2007). Personal values' influence on the ethical dimension of decision making. Journal of Business Ethics, 75(4), 335-343.

Gefen, D., \& Straub, D. (2005). A Practical Guide To Factorial Validity Using PLS-Graph: Tutorial And Annotated Example. Communications of the Association for Information Systems, 16(July), 91-109.

Giles-Corti, B., \& Donovan, R. J. (2002). The relative influence of individual, social and physical environment determinants of physical activity. Social Science and Medicine, 54(12), 1793-1812.

Greenfield, S., Kaplan, S. H., Ware, J. E., Yano, E. M., \& Frank, H. J. L. (1986). Patients' participation in medical care: Effects on Blood Sugar Control and Quality of Life in Diabetes. Journal of General Internal Medicine and Health Services Research, 3(5), 448-457.

Greysen, S. R., Kind, T., \& Chretien, K. C. (2010). Online professionalism and the mirror of social media. Journal of General Internal Medicine, 25(11), 1227-1229.

Godfrey, M. and Townsend, J. (2008), Older people in transition from illness to health: trajectories of recovery, Qualitative Health Research, 18(7), 939-951.

Goldman, E. F. (2008). The power of work experiences: Characteristics critical to developing expertise in strategic thinking. Human Resource Development Quarterly, 19(3), 217239.

Gould, S. J. (1988). Consumer attitudes toward health and health care: a differential perspective. Journal of Consumer Affairs, 22, 96-118.

Hair, J. F., Black, W. C., Babin, B. J., \& Anderson, R. E. (2010). Multivariate Data Analysis_sumario. Analysis, 816. doi: https://doi.org/10.1016/j.ijpharm.2011.02.019

Hair, J.F. Jr., William C. Black, B. J. B. and Anderson. R. E. (2014). Multivariate Data Analysis (MVDA). Pearson Education Limited. 


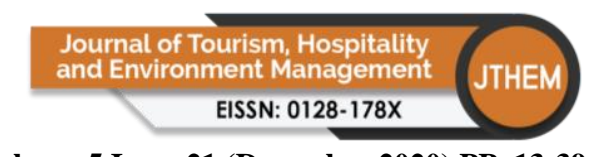

Volume 5 Issue 21 (December 2020) PP. 13-39 DOI 10/35631/JTHEM.521002

Haque, M. N., Soonthorndhada, K., Hunchangsith, P., \& Kanchanachitra, M. (2016). Active ageing level in Thailand: a comparison between female and male elderly. Journal of Health Research, 30(2), 99-107.

Health Care Asia (2017)._Malaysia's budding elderly care plays catch up with the ageing population. $\quad$ Retrieved 5ebruary 2018, from http://healthcareasiamagazine.com/healthcare/in-focus/malaysias-budding-elderlycare-plays-catch-ageing-population.

Heinemann, A. W. (2010). Measurement of participation in rehabilitation research. Archives of physical medicine and rehabilitation, 91(9), S1-S4

Henriksen, K., Isaacson, S., Sadler, B. L., \& Zimring, C. M. (2007). The role of the physical environment in crossing the quality chasm. The Joint Commission Journal on Quality and Patient Safety, 33(11), 68-80.

Holm, L. V., Hansen, D. G., Johansen, C., Vedsted, P., Larsen, P. V., Kragstrup, J., \& Søndergaard, J. (2012). Participation in cancer rehabilitation and unmet needs: A population-based cohort study. Supportive Care in Cancer, 20(11), 2913-2924.

Hong, H. (2011). An extension of the extended parallel process model (EPPM) in television health news: The influence of health consciousness on individual message processing and acceptance. Health Communication, 26(4), 343-353.

Humpel, N., Owen, N., \& Leslie, E. (2002). Environmental factors associated with adults' participation in physical activity. A review. American Journal of Preventive Medicine, $22(3), 188-199$.

Hong, H. (2009). Scale Development for Measuring Health Consciousness: Reconceptualization. 12th Annual International Public Relations Research Conference, University of Miami, Coral Gables, Florida, USA, 11-14 March 2009, 212-233.

Howell, R. T., Kurai, M., \& Tam, L. (2013). Money Buys Financial Security and Psychological Need Satisfaction: Testing Need Theory in Affluence. Social Indicators Research, 110(1), 17-29.

Index Murni (2019). Malaysia age structure. Retrieved Jun 18, 2020 from https://www.indexmundi.com/malaysia/age_structure.html.

Jang, S. S., \& Namkung, Y. (2009). Perceived quality, emotion, and behavioral intentions: Application of an extended Mehrabian-Russell model to restaurants. Journal of Business Research, 62(4), 451-460.

Karlsson, C. (2016). Research Methods for Operation Management (end). Routledge.

Karn, S., \& Swain, S. K. (2017). Health consciousness through wellness tourism : a new dimension to new age travelers '. African Journal of Hospitality, Tourism and Leisure, $6(3), 1-9$.

Kim, H., \& Lyons, A. C. (2008). No pain, no strain: Impact of health on the financial security of older Americans. Journal of Consumer Affairs, 42(1), 9-36.

Khan, R., \& Qureshi, M.S.H. (2018). The Three Dimensions of Health and Well Being. Journal of Community Medicine \& Health Education, 8(01), 586.

Kraft, F.B. \& Goodell, P.W. (1993). Identifying the health-conscious consumer. Journal of Health Care Marketing, 13(3), 18-25.

Lai, K. P., \& Chong, S. C. (2019). Do the servicescape of public and private hospitals differ? The Malaysian context. International Journal of Quality and Service Sciences. 11(3), 357-377. 


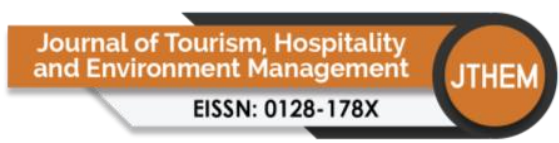

Volume 5 Issue 21 (December 2020) PP. 13-39 DOI 10/35631/JTHEM.521002

Lai, K. P., \& Chong, S. C. (2020). The influence of servicescape and service credibility on older adults' intention to recover. Journal of Health Organization and Management, 34(2), 101-122.

Lee, Y., \& Kasper, J. D. (1998). Assessment of medical care by elderly people: general satisfaction and physician quality. Health Services Research, 32(6), 741-758.

Leitan, N. D., Michalak, E. E., Berk, L., Berk, M., \& Murray, G. (2015). Optimizing delivery of recovery-oriented online self-management strategies for bipolar disorder: A review. Bipolar Disorders, 17(2), 115-127.

Leung, S. O. (2011). A comparison of psychometric properties and normality in 4-, 5-, 6-, and 11-point likert scales. Journal of Social Service Research, 37(4), 412-421.

Levasseur, M., Richard, L., Gauvin, L., \& Raymond, É. (2010). Inventory and analysis of definitions of social participation found in the aging literature: Proposed taxonomy of social activities. Social Science \& Medicine, 71(12), 2141-2149.

Lewin, J. E., \& Johnston, W. J. (1997). Relationship marketing theory in practice: A case study. Journal of Business Research, 39(1), 23-31.

Lim, E. Z., \& Thompson, C. L. (2016). Measuring active ageing among older adults in Singapore. Ageing \& Society, 36(9), 1853-1869.

Liu, W., Manias, E., \& Gerdtz, M. (2014). The effects of physical environments in medical wards on medication communication processes affecting patient safety. Health and Place, 26, 188-198.

Llewellyn-Beardsley, J., Rennick-Egglestone, S., Callard, F., Crawford, P., Farkas, M., Hui, A., Slade, M. (2019). Characteristics of mental health recovery narratives: Systematic review and narrative synthesis. PLoS One, 14(3), e0214678. doi: https://doi.org/10.1371/journal.pone.0214678

Mahmood, A., Chaudhury, H., \& Valente, M. (2011). Nurses' perceptions of how physical environment affects medication errors in acute care settings. Applied Nursing Research, 24, 229-237.

Marquet, O., \& Miralles-Guasch, C. (2015). Neighbourhood vitality and physical activity among the elderly: The role of walkable environments on active ageing in Barcelona, Spain. Social Science \& Medicine, 135(2015), 24-30.

Medical centre. (n.d.). Segen's Medical Dictionary. Retrieved February 20, 2020, from https://medical-dictionary.thefreedictionary.com/medical+centre

Mehrabian, A., \& Rusell, J. A. (1974). An approach to environment psychology. Cambridge, MA: MIT Pres

Methaq, A. S., (2015). The Effects of Brand Credibility on Customer's WOM Communication: The Moderator Role of Brand Commitment. European Journal of Business and Social Sciences, 4(9), 164-176.

Michaelidou, N., \& Hassan, L. M. (2008). The role of health consciousness, food safety concern and ethical identity on attitudes and intentions towards organic food. International Journal of Consumer Studies, 32(2), 163-170.

Michalos, A. C., Thommasen, H. V., Read, R., Anderson, N., \& Zumbo, B. D. (2005). Determinants of health and the quality of life in the Bella Coola Valley. Social Indicators Research, 72(2), 1-50.

MIMS (2017)._Malaysia's MOH says health spending per person has doubled in 17 years. Retrieved February 16, 2018, from https://today.mims.com/malaysia-s-moh-sayshealth-spending-per-person-has-doubled-in-17-years. 


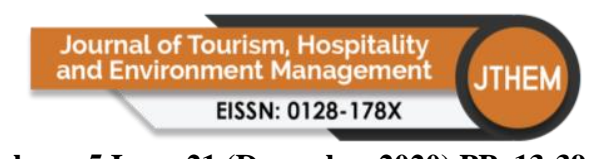

Volume 5 Issue 21 (December 2020) PP. 13-39 DOI 10/35631/JTHEM.521002

Morgan, R. M. and Hunt, S. D. (1994). The commitment-trust theory of relationship marketing, Journal of Marketing, 58(3), 20-38.

Morris, G. P., Beck, S. A., Hanlon, P., \& Robertson, R. (2006). Getting strategic about the environment and health. Public Health, 120(10), 889-903.

Mubashir Arain, Michael J Campbell, C. L. C. and G. A. L. (2010). What is a pilot or feasibility study? A review of current practice and editorial policy. BMC Medical Research Methodology, 10(1), 1-7.

Newsom, J. T., McFarland, B. H., Kaplan, M. S., Huguet, N., \& Zani, B. (2004). The health consciousness myth: Implications of the near independence of major health behaviors in the North American population. Social Science and Medicine, 60(2), 433-437.

Omidinia, S., Masrom, M., \& Selamat, H. (2011). Review of e-learning and ICT infrastructure in develop-ing countries (Case study of Iran). American Journal of Economics and Business Administration, 3(1), 120-125.

Pallant, J. F., \& Bailey, C. (2005). Assessment of the structure of the hospital anxiety and depression scale in musculoskeletal patients. Health and Quality of Life Outcomes, $3(82), 1-9$.

Petry, N. M. (2002). A comparison of young, middle-aged, and older adult treatment-seeking pathological gamblers. Gerontologist, 42(1), 92-99.

Plank, R.E. \& Gould, S.J. (1990) Health consciousness, scientific orientation and wellness; an examination of the determinants of wellness attitudes and behaviours. Health Marketing Quarterly, 7(3-4), 65-83.

Roslan, N. S., Yusoff, M. S. B., Ahmad, A. F., \& Mohd Hussin, Z. A. (2016). Together we stand, divided we fall: Interprofessional collaborative practice competencies from Malaysian medical professionals' perspectives. Journal of Taibah University Medical Sciences, 11(6), 533-540.

Rostami, F., Nadi, A., Abedi, G., Moosazadeh, M., Abedini, E., Khosravi Shadmani, F., \& Mansori, K. (2018). İran'ın Sari kentindeki hastanelerde hastaların güvenlik duygusu ve hizmet kalitesindeki boşluk arasındaki ilişki. Cukurova Medical Journal, 43(4), 958-966.

Seyed Ghorban, Z., \& Tahernejad, H. (2012). A Study on Effect of Brand Credibility on Word of Mouth: With Reference to Internet Service Providers in Malaysia. International Journal of Marketing Studies, 4(1), 26-37.

Shaver, J. M. (1998). Accounting for endogeneity when assessing strategy performance: Does entry mode choice affect FDI survival? Management Science, 44(4), 571-585.

Sheldon Greenfield, Sherrie Kaplan, J. E. W. (1984). Expanding Patient Involvement in Care. Annals of Internal Medicine, 102(4), 520-528.

Shivaji, C. (2015). Demographia World Urban Areas - Built Up Urban Areas or World Agglomerations. Demographia World Urban Areas, (January), 1-133.

Sia, C. Y., Lai, K. P., Noor, M. N. M., Ismail, H. Bin, Tong, D. Y. K., \& Yuen, Y. Y. (2018). The Influence of Hospital Service Credibility on Patients' Revisit Intention. Turkish Online Journal of Design Art and Communication, 8 (September 2018), 1315-1321. doi: https://doi.org/10.7456/1080sse/176

Sillence, E. and Briggs, P. (2015), "Trust and engagement in online health a timeline approach approach. Handb PsycholCommun Technol, 33(2015), 469-87

Solayappan, A., \& Jayakrishnan, J. (2010). Key Determinants of Brand-Customer Relationship in Hospital Industry. Petroleum-Gas University of Ploiesti Bulletin, 62(4), 119-128. 


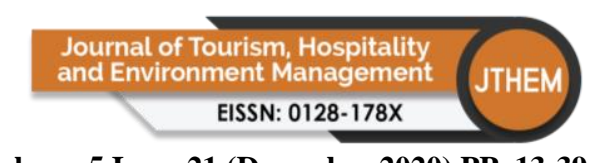

Volume 5 Issue 21 (December 2020) PP. 13-39 DOI 10/35631/JTHEM.521002

Sonğur, C., Özer, Ö., Gün, Ç., \& Top, M. (2018). Patient safety culture, evidence-based practice and performance in nursing. Systemic Practice and Action Research, 31(4), 359-374.

Saifee, D., Bardhan, I., Lahiri, A., \& Zheng, Z. (2019). Care Quality, Technology Use, and Online Patient Perception. Proceedings of the 52nd Hawaii International Conference on System Sciences, 6, 6697-6706. https://doi.org/10.24251/hicss.2019.801

Sundar, S.S. (2015), The Handbook of the Psychology of Communication Technology, 32, 467487. John Wiley \& Sons.

Staats, H., Kieviet, A. and Hartig, T. (2003), Where to recover from attentional fatigue: an expectancyvalue analysis of environmental preference, Journal of Environmental Psychology, 23(2), 147-157.

Tabachnick, B. G., Fidell, L. S., \& Ullman, J. B. (2007). Using multivariate statistics. Boston, MA: Pearson

Tedre, M., Ngubuke, F., \& Kempainnen, J. (2010). Infrastructure, human capacity and high hope: A decade of development of e-learning in a Tanzanian HEI. Revista de Universidady Sociedad del Cono-cimniento, 8(1), 7-20.

The Borneo Post (2017). Budget 2017: Increase in BR1M aid across the board. Retrieved February 16, 2018, from http://www.theborneopost.com/2016/10/21/budget-2017increase-in-br1m -aid-across-the-board/.

The New Straits Times. (2017). RM1.7 billion allocated for welfare of children, senior citizens, disabled. $\quad$ Retrieved February 6, 2018, from https://www.nst.com.my/news/nation/2017/10/295852/rm17-billion-allocatedwelfare-children-senior-citizens-disabled

Tobi, S. M., Fathi, M. S., \& Amaratunga, D. (2017). Ageing in place, an overview for the lderly in Malaysia. In AIP conference proceedings. 1891(1), 020101-6. AIP Publishing LLC.

Trachtenberg, F., Dugan, E., \& Hall, M. A. (2005). How patients' trust relates to their involvement in medical care. The Journal of Family Practice, 54(4), 344-352.

Utusan Online. (2017). Transformasi Penjagaan Kesihatan Optimum. Retrieved February 6 , 2018, from_http://www.utusan.com.my/gaya-hidup/kesihatan/transformasi-penjagaankesihatan-optimum-1.590412.

Van Oerle, S., Mahr, D., \& Lievens, A. (2016). Coordinating online health communities for cognitive and affective value creation. Journal of Service Management, 27(4), 481506.

Wang, W., Chen, R. R., Ou, C. X., \& Ren, S. J. (2018). Media or message, which is the king in social commerce?: An empirical study of participants' intention to repost marketing messages on social media. Computers in Human Behavior, 93(2019), 1-36.

Warta Daily, (2017). Cadangan Akta Warga Emas Bagi Melindungi Hak Golongan Itu Kata Rohani Karim. Retrieved February 6, 2018, from http://wartadaily.com.my/aktrawarga-emas-bagi-melindungi-hak-golongan-itu-kata-rohani-karim/.

Whiter, K.A. (2020). Strategies for Engaging Students in the Online Environment. IGI Global: Disseminator of Knowledge.

Williams, M. J., Mayer, R., \& Minges, M. (2011). Africa's ICT infrastructure building on the mobile revolution. The World Bank. Retrieved May 5, 2013 from http://siteresources.worldbank.org/INFORMATIONANDCOMMUNICATIONANDT ECHNOLOGIES/Resources/AfricasICTInfrastructure_Building_on_MobileRevolutio n_2011.pdf. 
World Health Organization. Office of World Health Reporting. (2002). Promoting healthy life overview: World Health Organization. Retrieved June 8, 2018, from https://apps. who.int/iris/handle/10665/67454 [2018, June 8].

World Health Organization. Definition of an older or elderly person. Geneva, Switzerland: WHO; (2010). Retrieved November 22, 2018, from http://www.who.int/healthinfo/survey/ageingdefnolder/en/index.html World Health Organization, (2011). Rehabilitation. Retrieved November 22, 2018, from http://www.who.int/topics/rehabilitation/en.

Wu, Y. T., Prina, A. M., Jones, A. P., Barnes, L. E., Matthews, F. E., \& Brayne, C. (2015). Community environment, cognitive impairment and dementia in later life: results from the Cognitive Function and Ageing Study. Age and ageing, 44(6), 1005-1011.

Xiao, J. J., \& Noring, F. (1994). Perceived saving motives and hierarchical financial needs. Financial Counseling and Planning, 5(1), 25-44.

Young, M., \& Klingle, R. S. (1996). Silent Partners in Medical Care: A Cross-Cultural Study of Patient Participation Marti. Health Communication, 8(1), 29-53.

Young, D. W., Dembo, R., \& Henderson, C. E. (2007). A national survey of substance abuse treatment for juvenile offenders. Journal of Substance Abuse Treatment, 32(3), 255266.

Zaidi, A., Gasior, K., Zolyomi, E., Schmidt, A., Rodrigues, R., \& Marin, B. (2017). Measuring active and healthy ageing in Europe. Journal of European Social Policy, 27(2), 138157. 